\title{
5-Hydroxymethylfurfural Oxidation Over Platinum Supported on Açaí Seed Coal for Synthesis of 2,5- Furandicarboxylic Acid
}

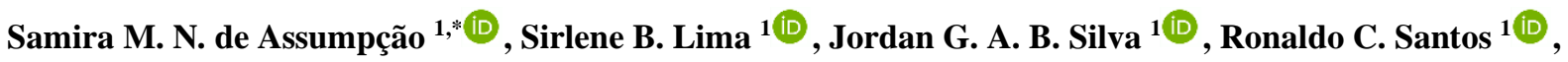 \\ Leila M. A. Campos ${ }^{2(\mathbb{D}}$, José M. Ferreira Jr ${ }^{3(\mathbb{D}}$, Gustavo F. Trindade ${ }^{4(\mathbb{D}}$, Mark A. Baker ${ }^{5(\mathbb{D})}$, Luiz A. \\ M. Pontes 1 (iD) \\ 1 Postgraduate Program in Chemical Engineering, Polytechnic School, Federal University of Bahia, 40210-630, Salvador, \\ Bahia, Brazil \\ 2 Department of Chemical Engineering, Salvador University, 41940-060, Salvador, Bahia, Brazil \\ 3 Aveiro Institute of Materials, University of Aveiro, 3810-193, Aveiro, Portugal \\ 4 Centre for Additive Manufacturing, Faculty of Engineering, School of Pharmacy, University of Nottingham, NG7 2RD, \\ United Kingdom \\ 5 The Surface Analysis Laboratory, Faculty of Engineering and Physical Sciences, University of Surrey, Surrey GU2 4DL, \\ United Kingdom \\ * Correspondence: samira.assumpcao@gmail.com (S.M.N.A.);
}

Received: 26.05.2021; Revised: 10.09.2021; Accepted: 15.09.2021; Published: 19.11.2021

\begin{abstract}
FDCA) is produced from the selective oxidation of 5hydroxymethylfurfural (HMF) and is an important platform molecule applied in the pharmaceutical and petrochemical industries. Activated carbons produced from renewable resources are useful materials due to their physicochemical properties, defined mainly by the oxygenated functional groups on their surface. This work studies the oxidation of HMF to FDCA over Pt catalysts supported on açaí coal. The catalysts were characterized by $\mathrm{N}_{2}$ adsorption, XPS, ToF-SIMS, FTIR, XRD, Raman, TEM, SEM, TPR$\mathrm{H}_{2}$, and TGA/DTA. The conversion of HMF to FDCA in an alkaline medium occurred via hydroxymethyl-2-furancarboxylic acid (HMFCA), which was oxidized to 5-formylfurancarboxylic acid (FFCA) and FDCA. The catalytic tests showed a high conversion of HMF with a 93.6\% yield of FDCA. The excellent results were attributed to the high dispersion of $\mathrm{Pt}$ on the support and the presence of oxygenated functional groups on the coal surface. The functional groups increased the interaction between Pt-HMF and Pt-furan intermediates and favored a higher dispersion of platinum $(53.3 \%)$ due to an anchoring effect.
\end{abstract}

Keywords: 2,5-furandicarboxylic acid; 5-hydroxymethylfurfural; oxidation; platinum/CAK.

(C) 2021 by the authors. This article is an open-access article distributed under the terms and conditions of the Creative Commons Attribution (CC BY) license (https://creativecommons.org/licenses/by/4.0/).

\section{Introduction}

The conversion of lignocellulosic biomass into platform molecules is increasingly attractive in the sustainable production of biofuels, petrochemicals, and fine chemicals. 2,5furandicarboxylic acid (FDCA) is a biomolecule with an estimated potential value of 786.3 million US $\$$ by 2027, with a compound annual growth rate (CAGR) of $8.7 \%$ [1], which can be used in the synthesis of drugs, fungicides, and corrosion inhibitors, but is particularly important in the synthesis of polymers (polyesters, polyamides, and polyurethanes) [2,3]. The similarity of the chemical structure of FDCA with terephthalic acid, the main component in the synthesis 
of polyethylene terephthalate (PET) and fibers, allows its use as a substitute for this molecule in the production process.

The selective oxidation of HMF is a promising route for the production of FDCA [35]. The main goal is to increase the selectivity to the FDCA since it involves a multi-stage process with the formation of several intermediates, among them hydroxymethyl-2furancarboxylic acid (HMFCA), 5-formylfurancarboxylic acid (FFCA), or 2,5-diformylfuran (DFF). Heterogeneous catalysts containing noble metals ( $\mathrm{Ru}, \mathrm{Pt}, \mathrm{Pd}$, and $\mathrm{Au}$ ), as the active component, supported on different materials, have been evaluated for this reaction [6-8], but platinum is the most used [5, 9-11]. Among the commonly used supports are metal oxide [3,12] and activated carbon $[3,13,14]$.

Carbonaceous materials are used in various oxidation reactions due to their excellent physicochemical properties, combined with a surface rich in functional groups, increasing catalytic activity. The effect exerted by these groups on the oxidation of HMF is observed by the incorporation of other elements in the supports, such as nitrogen and oxygenated species $[6,15-18]$ to change their adsorption properties. Zhou et al. [15] used Pt supported on carbon nanotubes (CNT) functionalized with quinones and phenolic groups, obtaining a 98\% selectivity in FDCA, while Sharma et al. [6] used Pt/CNT functionalized with hydroxyl groups and also observed a 98\% selectivity in FDCA. Donoeva et al. [16] evaluated Au catalysts supported on high surface area graphite charcoal (HSAG) enriched with nitrogenous species, reaching a yield of $75 \%$ for FDCA.

Activated carbon produced from agro-industrial waste is an attractive alternative because it is low cost and has interesting physicochemical properties. Açaí seeds and fruit residues, abundant in the Amazon, have been used in many studies [19-21]. Examples include the synthesis of coal aimed at the adsorption of phenol in aqueous solution [22], the adsorption of metal ions $\left(\mathrm{Cu}^{2+}\right.$ and $\left.\mathrm{Zn}^{2+}\right)$ in contaminated solutions from industrial and agricultural activities [23], and the synthesis of biochar to promote improvements in soil quality [19]. The açaí seed has a high content of carbon and volatile compounds and low contents of inorganic species $[19,21]$; hence it is considered biomass with characteristics suitable for the production of activated carbon.

In this context, this work studies the selective oxidation of HMF to FDCA on Pt catalysts supported on açaí seed coal (Pt/CAK). The use of the açaí seed for activated carbon production is environmentally friendly and has not been reported as a catalyst or support material in this reaction until now. The catalytic activity involved in the transformation of HMF was related to its chemical, textural, and structural properties, and the effects of these properties on the FDCA yield were evaluated.

\section{Materials and Methods}

\subsection{Catalyst synthesis.}

Two different catalysts were prepared with different activated carbon supports. The first support was commercial activated carbon (Calgon F600-CA), and the second support (CAK) was prepared using coal produced from the açaí seed (Euterpe Oleracea). The CAK was synthesized at the Laboratory of Oils of the Amazon (LOA) from the Federal University of Pará, Brazil, using the methodology adopted by Ello et al. [24].

Both activated carbon supports (CA and $\mathrm{CAK}$ ) were impregnated with an aqueous solution of $\mathrm{H}_{2} \mathrm{PtCl}_{6} .6 \mathrm{H}_{2} \mathrm{O}$ (40 wt\%; Sigma Aldrich) 10 g.L $\mathrm{L}^{-1}$ to obtain samples with $5 \%(\mathrm{w} / \mathrm{w})$ 
platinum in the final solid. The systems were heated to $80^{\circ} \mathrm{C}$ at $60 \mathrm{rpm}$ until the aqueous phase evaporated. Then, they were dried at $100^{\circ} \mathrm{C}$ for $24 \mathrm{~h}$. The catalysts were named Pt/CA and $\mathrm{Pt} / \mathrm{CAK}$ and stored in ambient conditions for subsequent reduction and use as catalysts.

\subsection{Characterization of the catalysts and supports.}

The supports and catalysts were characterized by elemental chemical analysis, measurements of specific surface area and porosity, X-ray diffraction (XRD), Raman spectroscopy, scanning electron microscopy (SEM), transmission electron microscopy (TEM), time-of-flight secondary ion mass spectrometry (ToF-SIMS), Fourier transform infrared spectroscopy (FTIR), X-ray photoelectron spectroscopy (XPS), programmed temperature reduction analysis $\left(\mathrm{TPR}-\mathrm{H}_{2}\right)$ and thermogravimetry (TGA/DTA). The metallic content of the catalysts was determined using energy dispersive X-ray fluorescence (EDXRF) employing a Bruker S2 Ranger instrument equipped with a palladium target X-ray tube under helium atmosphere, an acquisition time of $200 \mathrm{~s}$, and voltage of $50 \mathrm{kV}$. The analytical lines used to determine the Pt content were at $9.44 \mathrm{keV}$ (Ka spectral line). A Cu $250 \mu \mathrm{m}$ filter was employed in the EDXRF measurements for improving the peak-to-background ratio, resulting in better analytical signals. The textural properties of the materials were determined through the $\mathrm{N}_{2}$ adsorption isotherm, conducted at $-193{ }^{\circ} \mathrm{C}$. Measurements were performed on a Quantachrome model Nova 2200e. Before analysis, the samples were degassed at $100{ }^{\circ} \mathrm{C}$ for $2 \mathrm{~h}$ and then at $200{ }^{\circ} \mathrm{C}$ for $6 \mathrm{~h}$ under vacuum. The specific surface area was obtained from the BrunauerEmmett-Teller (BET) method, the volume of the micropores by the t-plot method, and the pore size distribution using the BJH method, following the desorption.

XRD was performed using a Shimadzu diffractometer, model XRD-6100, employing monochromatic $\mathrm{Cu} \mathrm{K} \alpha$ radiation $\left(\lambda=1.5418 \AA\right.$ ), over a $2 \theta$ angular range of $20-80^{\circ}$, scanning speed of $0.4^{\circ} \cdot \mathrm{min}^{-1}$ and rotation of $60 \mathrm{rpm}$.

The amorphous and crystalline phases of the supports and catalysts were also analyzed by Raman spectroscopy. The Raman spectra were obtained using an NRS-5100 laser spectrometer model Jasco Raman, using a CCD detector, a $532.13 \mathrm{~nm}$ laser line, and a 20x objective lens, with a $6.2 \mathrm{~mW}$ laser power.

The morphological analysis of the materials was evaluated by SEM. The samples were deposited on carbon tape and then coated with a thin layer of gold under a vacuum. The micrographs were obtained in a JOEL Microscope model JSM-6610 LV, with an acceleration voltage of $15 \mathrm{kV}$ and at $1500 \mathrm{x}$ magnification.

The metallic dispersion and particle size distribution were measured by TEM using a TECNAI G2 S-TWIN microscope, with an acceleration voltage of $200 \mathrm{keV}$. The metallic dispersion was calculated by the methodology described by Wang and Zhu [25].

ToF-SIMS analysis, powder samples of CA, CAK, Pt/CA and Pt/CAK were studied. ToF-SIMS analysis of positively and negatively charged secondary ions was carried out using an ION-TOF TOF.SIMS V spectrometer. For each sample, spectra were acquired using a 25 $\mathrm{keV} \mathrm{Bi}^{3+}$ primary ion beam operated in the high current bunched mode, delivering a current of $0.3 \mathrm{pA}$ and raster-scanned. The total dose was less than the static limit 1012 ions.cm ${ }^{-2}$. A lowenergy $(20 \mathrm{eV})$ electron flood gun was employed to neutralize charge build-up. To account for variability, 6 spectra were acquired from different regions of each sample. Control spectra of the adhesive tape substrate (used for sample mounting) were also measured. The mass scale was calibrated using the secondary ions (when present) $\mathrm{CH}_{3}{ }^{+}, \mathrm{C}_{2} \mathrm{H}_{5}{ }^{+}, \mathrm{C}_{3} \mathrm{H}_{5}{ }^{+}, \mathrm{C}_{4} \mathrm{H}_{7}{ }^{+}, \mathrm{C}_{5} \mathrm{H}_{7}{ }^{+}$, $\mathrm{C}_{6} \mathrm{H}_{9}{ }^{+}, \mathrm{Pt}^{+}$and $\mathrm{PtO}_{2}{ }^{+}$for positive spectra and $\mathrm{C}^{-}, \mathrm{CH}^{-}, \mathrm{O}^{-}, \mathrm{C}_{2}^{-}, \mathrm{C}_{2} \mathrm{H}^{-}, \mathrm{C}_{3}^{-}, \mathrm{C}_{3} \mathrm{H}^{-}$and $\mathrm{C}_{4} \mathrm{H}^{-}$for 
negative spectra. All ion assignments reported showed a deviation $(\Delta \mathrm{M} / \mathrm{M})$ of less than 100 ppm.

The surface composition of the studied samples was also analyzed by FTIR and XPS. The FTIR spectra were obtained in a Shimadzu IR Prestige-21 spectrophotometer, using diluted samples in a KBr pellet in the wavenumber region between 4000 and $400 \mathrm{~cm}^{-1}$. XPS analysis was carried out on a Thermo Scientific Theta Probe employing a monochromated Al Ka source, operated at $15 \mathrm{keV}$ and $20 \mathrm{~mA}$ and using a $400 \mu \mathrm{m}$ spot size. For all spectra, a $0.2 \mathrm{eV}$ step size was employed. XPS survey spectra were acquired at pass energy of $100 \mathrm{eV}$ and core level (C $1 s, \mathrm{O} 1 s, \mathrm{Cl} p, \mathrm{~S} 2 p, \mathrm{Pt} 4 f, \mathrm{~K} 2 p$, and $\mathrm{Si} 2 p$ ) narrow scans recorded using a pass energy of 50 $\mathrm{eV}$. Quantitative chemical compositions were calculated from the high-resolution core-level spectra, following the removal of a non-linear 'Smart' (Shirley) background and the use of instrument-modified sensitivity factors. Elemental concentrations were calculated assuming a homogeneous mixture of the elements over the analysis depth.

The reduction profiles of the catalysts were obtained by Thermoprogrammed Reduction (TPR- $\mathrm{H}_{2}$ ). Before analysis, the samples were pretreated in an atmosphere of Air/ $\mathrm{N}_{2}$ (flow rate $\left.30 \mathrm{~mL} \cdot \mathrm{min}^{-1}\right)$, heating from room temperature to $200{ }^{\circ} \mathrm{C}\left(10^{\circ} \mathrm{C} \cdot \mathrm{min}^{-1}\right)$, and it was kept at 200 ${ }^{\circ} \mathrm{C}$ for $30 \mathrm{~min}$. After cooling, the samples were subjected to heating from room temperature to $800{ }^{\circ} \mathrm{C}\left(10{ }^{\circ} \mathrm{C} \cdot \mathrm{min}^{-1}\right)$ in an atmosphere of $\mathrm{H}_{2} / \mathrm{N}_{2}\left(50 \mathrm{~mL} \cdot \mathrm{min}^{-1}\right)$.

The Thermogravimetric Analysis (TGA/DTA) was carried out under a nitrogen atmosphere in the temperature range of $25-600{ }^{\circ} \mathrm{C}$ at a rate of $10{ }^{\circ} \mathrm{C} . \mathrm{min}^{-1}$. The curves were obtained on a Shimadzu DTG-60 thermogravimetric analyzer.

\subsection{Catalytic evaluation.}

Before the HMF oxidation reaction, the catalysts with Pt supported on commercial coal $(\mathrm{Pt} / \mathrm{CA})$, and açaí coal $(\mathrm{Pt} / \mathrm{CAK})$ was reduced in a glass reactor at a temperature of $300{ }^{\circ} \mathrm{C}$ under a continuous flow of $50 \mathrm{~cm}^{3} \cdot \mathrm{min}^{-1}$ of $5 \% \mathrm{H}_{2} / \mathrm{N}_{2}$ (White Martins, both $99.999 \%$ ) for $3 \mathrm{~h}$. The reduced catalyst $(0.3 \mathrm{~g})$ was transferred to a batch-type Top Industry reactor $(100 \mathrm{~mL})$, containing an aqueous solution of HMF (10 g.L.-1) and $\mathrm{NaHCO}_{3}$ (P.A; Synth) in the mass proportions of 1:2. Sodium bicarbonate $\left(\mathrm{NaHCO}_{3}\right)$ was used to dissolve the acids formed and neutralize the reaction media, preventing acid deposition on the catalyst's surface. Oxidation of HMF was carried out at $100{ }^{\circ} \mathrm{C}$ for $4 \mathrm{~h}$, under a pressure of $40 \mathrm{bar}$ in an atmosphere of synthetic air (White Martins, $21 \% \mathrm{O}_{2}$ and $79 \% \mathrm{~N}_{2}$ ) and agitation of $700 \mathrm{rpm}$ to reduce the limiting effects of mass transfer. At the end of this process, an aliquot was filtered (PTFE filters $0.22 \mu \mathrm{m}$ ), diluted by 10x, and analyzed by the same HPLC equipment, detector (IR) and Aminex column (HPX-87H, Biorad-USA) and mobile phase $5 \mathrm{mM} \mathrm{H}_{2} \mathrm{SO}_{4}$, with $0.45 \mathrm{~mL} . \mathrm{min}^{-}$ ${ }^{1}$ flow and temperature of $50{ }^{\circ} \mathrm{C}$. The following species were quantified: FDCA (> 97\%, ChemImpex), 5-formylfurancarboxylic acid (FFCA grade; Sigma Aldrich), 2,5-diformylfuran (DFF> 98\%; TCI Chemical), hydroxymethyl-2- furancarboxylic acid (HMFCA> 97\%; ChemImpex) and HMF (HPLC grade; Sigma Aldrich).

The conversion and yield results of the desired species were calculated using equations (1) and (2).

Conversion $[\%]=$ mol substrate consumed $/ \mathrm{mol}$ substrate added

Yield $[\%]=$ mol product produced $/$ mol substrate consumed 


\section{Results and Discussion}

The $\mathrm{N}_{2}$ adsorption isotherms and the pore distribution of the supports and catalysts are shown in Figure S1 (Supplementary Materials). Both supports and catalysts presented type I isotherms, typical of microporous materials with mesopores [26].

These adsorption isotherms exhibit a marked increase in the adsorption of $\mathrm{N}_{2}$ at low relative pressures $\left(\mathrm{P} / \mathrm{P}_{0}<0.2\right)$ due to the filling of the micropores. At higher relative pressures $\left(0.4<\mathrm{P} / \mathrm{P}_{0}\right)$, the isotherms have an $\mathrm{H} 4$ type hysteresis loop [26, 27].

The surface areas and the metallic content of the supports and catalysts are shown in Table 1.

Table 1. Textural properties of supports and catalysts and Pt content of the catalysts.

\begin{tabular}{|c|c|c|c|c|c|c|}
\hline Catalyst & $\begin{array}{c}\mathrm{S}_{\text {BET }}{ }^{1} \\
\left(\mathrm{~m}^{2} \mathrm{~g}^{-1}\right)\end{array}$ & $\begin{array}{c}\text { SMICRO }^{2} \\
\left(\mathrm{~m}^{2} \mathrm{~g}^{-1}\right)\end{array}$ & $\begin{array}{l}\text { VMICRO }^{2} \\
\left(\mathrm{~cm}^{3} \mathrm{~g}^{-1}\right)\end{array}$ & $\begin{array}{l}\text { VMESo } \\
\left(\mathrm{cm}^{3} \mathrm{~g}^{-1}\right)\end{array}$ & $\begin{array}{l}V_{\text {TOTAL }}{ }^{2} \\
\left(\mathrm{~cm}^{3} \mathrm{~g}^{-1}\right)\end{array}$ & Pt content (at.\%) \\
\hline CAK & 1106 & 995 & 0.4 & 0.1 & 0.5 & -- \\
\hline $\mathrm{Pt} / \mathrm{CAK}$ & 858 & 770 & 0.3 & 0.1 & 0.4 & 5.2 \\
\hline CA & 929 & 807 & 0.3 & 0.1 & 0.4 & -- \\
\hline $\mathrm{Pt} / \mathrm{CA}$ & 745 & 658 & 0.3 & 0.1 & 0.4 & 4.8 \\
\hline
\end{tabular}

${ }^{1}$ Calculated by BET method ${ }^{2}$ Calculated by T-plot method ${ }^{3}$ Calculated by difference $\left(\mathrm{V}_{\text {MESO }}=\mathrm{V}_{\text {TOTAL }}-\mathrm{V}_{\text {MICRO }}{ }^{4}\right.$ Determined by EDXRF

The supports and catalysts had a high specific surface area. Micropores contribute significantly to the value of this area (CAK and $\mathrm{Pt} / \mathrm{CAK} \approx 90 \%$ and $\mathrm{CA}$ and $\mathrm{Pt} / \mathrm{CA} \approx 88 \%$ ).

After incorporating platinum into the supports $(5 \% \mathrm{w} / \mathrm{w})$, a $20 \%$ decrease in the surface area of the catalyst micropores was observed. From this, it can be inferred that the deposition of platinum occurred on the surface of the micropores, partially obstructing the channels, decreasing the capacity for adsorption of $\mathrm{N}_{2}$ molecules by the catalysts. Sharma et al. [6], working with a CNT support containing $\mathrm{Pt}, \mathrm{Ru}, \mathrm{Pd}, \mathrm{Co}$, and $\mathrm{Ni}$ for the aerobic oxidation of $\mathrm{HMF}$, observed that, after the impregnation and drying of the catalysts, there was a decrease in the specific surface area. The authors attributed this reduction to a blockage of CNT micropores by forming clusters of metallic particles during heat treatment.

The structure and effect of platinum incorporation on the coals (CA and CAK) were analyzed by XRD (Figure 1).



(a)

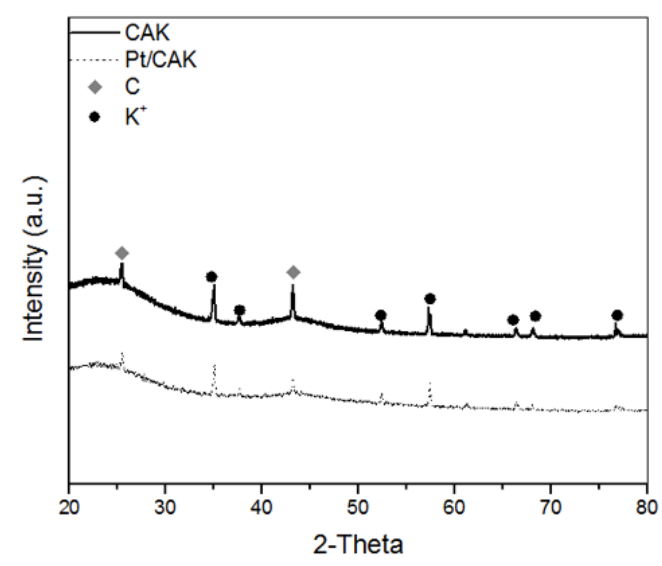

(b)

Figure 1. X-ray diffractograms of the supports and Pt catalysts on the supports: (a) CA coal; (b) CAK coal; ( $\bullet$ ) activated carbon $(\bullet)$ Potassium oxide and carbonate compounds.

The diffractograms of CA, CAK, Pt/CA and Pt/CAK showed two amorphous humps $\left(2 \theta=20-30^{\circ}\right.$ and $\left.40-50^{\circ}\right)$ typical of activated carbon [28], and a peak at $2 \theta=25^{\circ}$ due to the 
graphitic carbon $(002)$ reflection [28,29]. Peaks attributable to metallic platinum were not observed, suggesting that it is highly dispersed in the supports [30].

Peaks related to the activating agent $(\mathrm{KOH})$ were observed only in the CAK and the catalyst prepared with this support. The peaks centered at $2 \theta=37.6^{\circ}$ are attributed to the presence of $\mathrm{K}_{2} \mathrm{CO}_{3}$ and at $34.9^{\circ}$ to hydrated potassium carbonate $\left(\mathrm{K}_{2} \mathrm{CO}_{3} \cdot 1.5 \mathrm{H}_{2} \mathrm{O}\right)$ [31]. The last peaks at $2 \theta=52.4^{\circ}, 57.2^{\circ}, 66.3^{\circ}, 68.07^{\circ}$ and $76.8^{\circ}$ are attributed to the potassium peroxide $\left(\mathrm{KO}_{2}\right)$ (JPDS 01-089-5948) and potassium ozonide $\left(\mathrm{KO}_{3}\right)$ (JPDS 01-077-1270). According to Mopoung et al. [31] the appearance of $\mathrm{KO}_{2}$ is due to the partial oxidation of the graphite-potassium bond by the functional groups $(\mathrm{C}-\mathrm{O}-\mathrm{C}$ or $\mathrm{C}-\mathrm{O}-\mathrm{H})$ present in coal.

The presence of these species indicates that even after washing the material, $\mathrm{K}^{+}$ions remained in their structure. Villa et al. [32] evaluated the effect of the potassium ion on a $\mathrm{Au} /$ (carbon nanofiber, $\mathrm{CNF}$ ) catalyst for HMF oxidation. It was found that the incorporation of $\mathrm{K}^{+}$ions in the CNF structure did not affect the catalytic activity.

Raman spectra of the supports and catalysts are presented in Figure 2, showing characteristic D and $\mathrm{G}$ bands of carbonaceous materials in the region of 1000-2000 $\mathrm{cm}^{-1}$ [29]. At around $1580 \mathrm{~cm}^{-1}$, the $\mathrm{G}$ band (graphite band) is generally attributed to the bond stretching of $\mathrm{sp}^{2}$ carbon pairs either in aromatic rings or chains [29,33]. The D band (disorder band) is associated with the discontinuity of the graphite layers or network defects and occurs at around $1350 \mathrm{~cm}^{-1}[29,34]$. The disorder is linked to the breakdown of $\mathrm{sp}^{2}$-type bonds and the formation of $\mathrm{sp}^{3}$-type bonds, the presence of oxygenated groups, and vacancies or heteroatoms on the surface of the activated carbon materials.



(a)

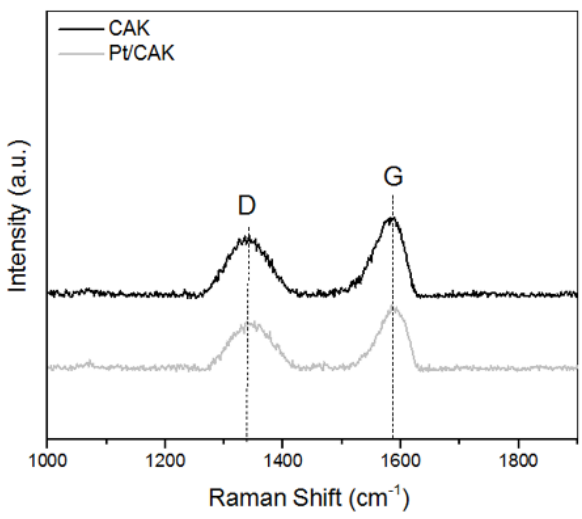

(b)

Figure 2. Raman spectra of materials obtained with (a) CA coal; (b) CAK coal.

From Figure 2, it can be noted that in both the support and catalyst, the incorporation of Pt has not altered the structure of the supports, as observed in the X-ray diffractograms, due to the preservation of shape of the $\mathrm{D}$ and $\mathrm{G}$ bands in these materials.

The catalyst supported by CAK (Figure $2 b$ ) showed broader and less intense peaks than the CA coal-supported catalyst (Figure 2a). The wider D band indicates the presence of the heteroatoms and impurities that contribute to the material disorder [23,35].

Figure 3 presents TEM images, SEM images, and histograms of the particle size distribution for the Pt/CA (Figure 3a) and Pt/CAK (Figure 3b) catalysts.

The Pt catalysts morphologies are very similar to the supports, as can be seen in the SEM images in Figure 3 and Figure S-2 (Supplementary Materials), respectively. This behavior indicates that the impregnation of Pt did not change the morphology of the coals. For the TEM images (Figure 3), both catalysts showed a predominance of Pt nanoparticles with an average diameter between 2-3 $\mathrm{nm}$. 


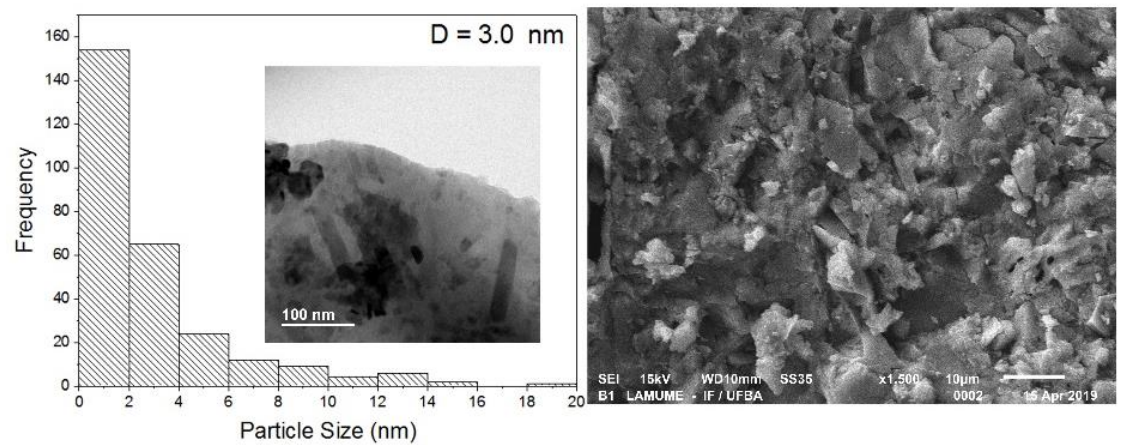

(a)



(b)

Figure 3. TEM images and particle size histograms (left) and SEM images (right) of the Pt catalysts: (a) Pt/CA; (b) $\mathrm{Pt} / \mathrm{CAK}$.

The Pt/CAK catalyst (Figure $3 \mathrm{~b}$ ) had a smaller average particle diameter $(2.1 \mathrm{~nm})$ and higher metallic dispersion (53.3\%) than the Pt/CA catalyst (Figure 3a), with an average particle diameter of $3.0 \mathrm{~nm}$ and dispersion of $37.7 \%$.

The formation of Pt particles of different medium sizes in the CA and CAK supports can be attributed to the different nature and concentrations of oxygenated groups on the surface of the supports. The oxygenated surface groups on the support can interact with the metallic precursor $\left(\left[\mathrm{PtCl}_{6}\right]^{2}\right)$, affecting the metallic dispersion metallic [36,37].

A study of the relative amount of oxygen, hydrogen, and platinum-containing secondary ions in the catalysts was obtained by ToF-SIMS (Figure 4).

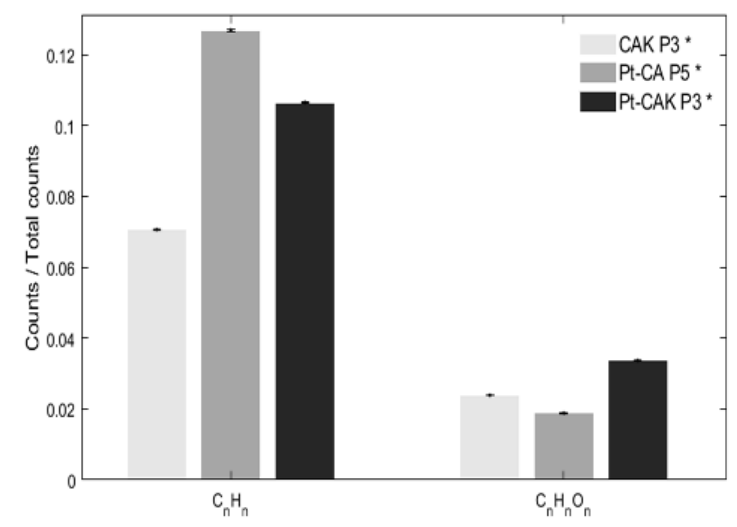

(a)

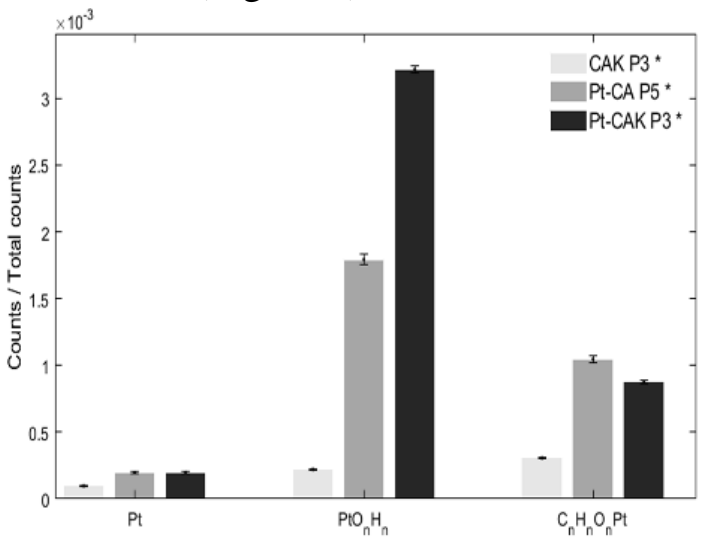

(b)

Figure 4. Relative concentrations of ToF-SIMS: (a) fragments hydrocarbons and oxygen-containing hydrocarbons; (b) Platinum-based species.

ToF-SIMS analysis revealed that CAK and Pt/CAK have a higher relative amount of oxygen-containing organic species in comparison to Pt/CA (Figure 4a). This is evidenced in Figure $4 \mathrm{a}$, which shows the normalized counts of all identified hydrocarbons and oxygencontaining secondary ions $\left(\mathrm{C}_{\mathrm{n}} \mathrm{H}_{\mathrm{n}}{ }^{+}\right.$and $\mathrm{C}_{\mathrm{n}} \mathrm{H}_{\mathrm{n}} \mathrm{O}_{\mathrm{n}}{ }^{+}$, respectively). 
Moreover, Figure $4 b$ shows that secondary ions of the kind $\mathrm{PtO}_{\mathrm{n}} \mathrm{H}_{\mathrm{n}}$ are more intense for $\mathrm{Pt} / \mathrm{CAK}$. Only oxide and hydroxide forms of secondary platinum ions are detected, with a much lower intensity for $\mathrm{Pt}^{+}$(attributed to metallic platinum). These results indicate that $\mathrm{CAK}$ has more binding/oxygen sites available for the formation of platinum oxide/hydroxide, leading to better catalyst performance in relation to $\mathrm{CA}$.

Figure S-3 (Supplementary Materials) also showed that CAK coal and the Pt/CAK catalyst presented strong $\mathrm{K}+$ and $\mathrm{KOH}+$ secondary ions signals. The nature of the oxygencontaining functional groups in the supports and catalysts was studied by FTIR (Figure 5).

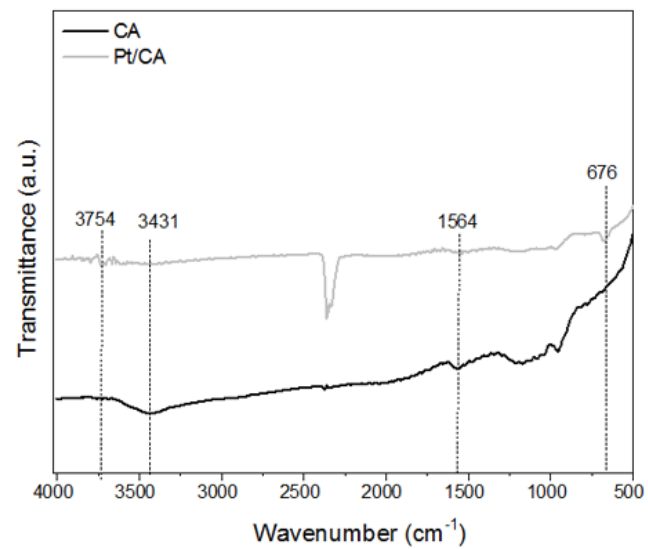

(a)

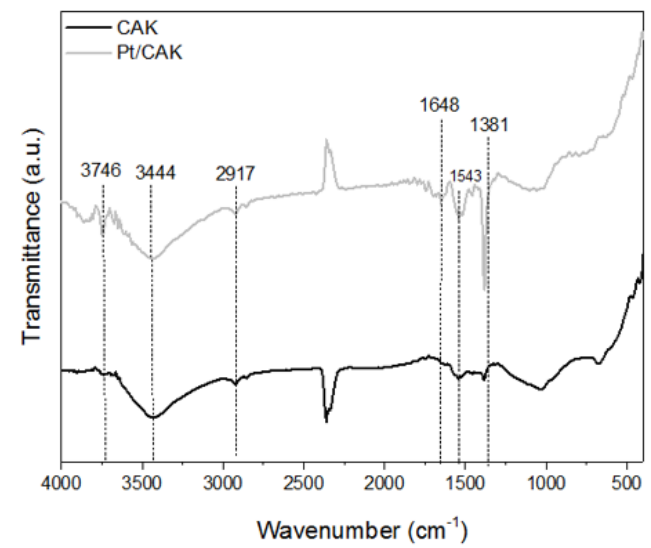

(b)

Figure 5. FTIR spectra of supports and Pt catalysts on the supports: (a) CA coal; (b) CAK coal.

In Figure 5, bands between $3000-3750 \mathrm{~cm}^{-1}$ are observed on all supports and catalysts. These bands are attributed to the presence of hydroxyl $(\mathrm{OH})$ bonds, such as physisorbed water, phenols, alcohols, and carboxylic acids present on the surface of these materials [38,39]. In the CAK spectra (Figure $5 \mathrm{~b}$ ), these bands are more intense, suggesting a greater presence of oxygen-containing groups, as observed in the ToF-SIMS analysis.

The bands close to $1500 \mathrm{~cm}^{-1}$ are attributed to the elongation of the $\mathrm{C}=\mathrm{C}$ bond, indicating the existence of single or multiple aromatic rings in the structure of the solids [40], and in the band at $676 \mathrm{~cm}^{-1}$ (Figure 5a) relative to $\mathrm{C}-\mathrm{H}$ out of plane bending aromatic rings $[27,41]$.

In the spectra of CAK and Pt/CAK solids (Figure 5b), the band at $1381 \mathrm{~cm}^{-1}$ is associated with the presence of phenolic structures due to the $\mathrm{OH}$ deformation $[42,43]$. The band at $1648 \mathrm{~cm}^{-1}$ is attributed to carboxylic acids, ketones, and aldehydes [23,41,44,45], and the band at $2917 \mathrm{~cm}^{-1}$ suggests the presence of $\mathrm{sp}^{3}$ carbon chains (aliphatic chains). Spectral bands located between $2850-2970 \mathrm{~cm}^{-1}$ correspond to the elongation of aliphatic functional groups $(\mathrm{CH})$ [46] and asymmetric methylene groups $\left(\mathrm{CH}_{2}\right)[40,44,45]$. Aliphatic carbon chains come from the cellulose and hemicellulose $\left(-\mathrm{CH}_{2}\right)$ fractions of the açaí residue, which were not fully converted into aromatic groups during the carbonization process.

From the XPS analysis, the interaction of platinum with the oxygenated groups present on the surface of the coals was studied. For this, peak fits of the $\mathrm{C} 1 \mathrm{~s}$ and oxygen $\mathrm{O} 1 \mathrm{~s}$ spectra were performed. Figure 6 shows the peak fitted $\mathrm{C} 1 \mathrm{~s}$ and $\mathrm{O}$ 1s spectra for the Pt/CA (Figure 6a and $6 \mathrm{~b}$ ) and Pt /CAK (Figure 6c and 6d) catalysts.

The $\mathrm{C} 1 \mathrm{~s}$ XPS peak shapes for the catalysts were similar, with a predominance $\mathrm{sp}^{2}$ hybridized $\mathrm{C}$ and some $\mathrm{sp}^{3}$ hybridized $\mathrm{C}$. It is generally accepted that the $\mathrm{sp}^{2} \mathrm{C}$ occurs at a slightly lower binding energy than the $\mathrm{sp}^{3} \mathrm{C}$, the difference in binding energy being approximately $0.4 \mathrm{eV}$. 




(a)



(c)

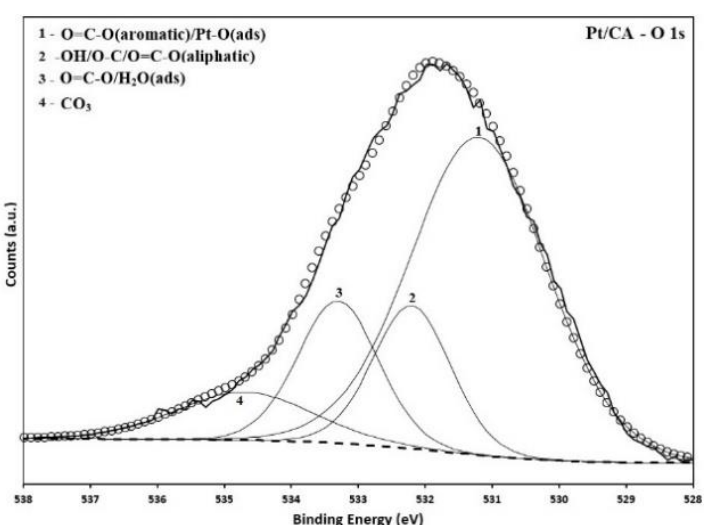

(b)

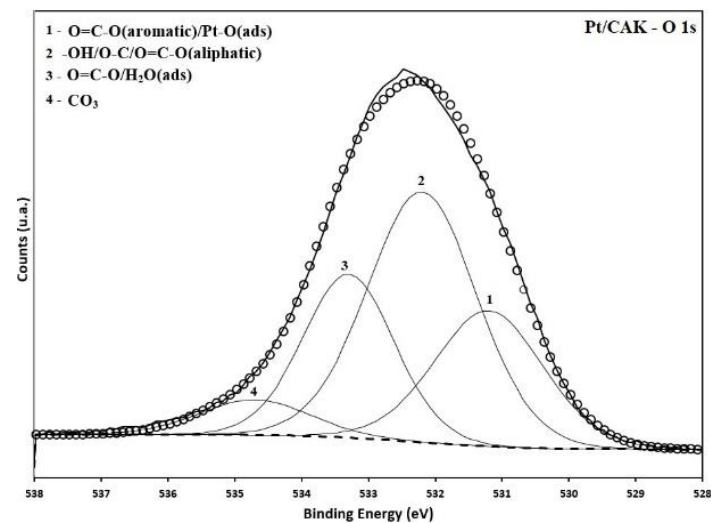

(d)

Figure 6. Peak fitted XPS C 1s and O 1s core-level spectra respectively for the Pt/CA (a, b); Pt/CAK (c, d) catalysts.

The peak at $284.6 \mathrm{eV}$, the strongest component, is attributed to graphitic/aromatic carbon [6], corroborating with the XRD and Raman results. The presence of many different oxygen-containing functional groups on the surface of these materials promoted the long tail of the $\mathrm{C} 1 \mathrm{~s}$ peak to higher binding energies, with no clear identifiable peaks. The overall intensity of this tail is higher for the Pt/CAK catalyst (Figure 6c) than that of the Pt/CA catalyst (Figure 6a), indicating a higher concentration of oxygen-containing functional groups, as observed in the FTIR spectra. The same behavior is observed in the XPS spectra of the supports, shown in Figure S4 (Supplementary Materials). The assignments for the different functional groups included in the $C$ 1s peak fits in Figure 6 are given in Table 2 and are based on known $\mathrm{C}$ 1s peak shifts in different polymers [47]. The low-intensity peak at higher binding energies is most likely associated with $\mathrm{O}$ in a highly oxidized environment, such as $\mathrm{CO}_{3}$.

The O1s spectra (Figure $6 \mathrm{~b}$ and $6 \mathrm{~d}$ ) can be fitted by four components: at 531.2, 532.2, 533.3, and $534.7 \mathrm{eV}$ (see Figure 6 inset and Table 2). The peak at $531.2 \mathrm{eV}$ is associated with the carbonyl-type $\mathrm{O}$ bonded through a $\mathrm{C}$ to an aromatic ring. Any oxidized (CA) or adsorbed $\mathrm{O}$ species on the Pt (see below) will also occur at this low binding energy. The larger peak for $\mathrm{CA}$ at this low binding energy is consistent with a greater concentration of oxide species on the $\mathrm{CA}$ support than CAK. The peak at $532.2 \mathrm{eV}$ relates to alcohol/ether oxygen $(\mathrm{C}-\mathrm{OH} / \mathrm{C}-\mathrm{O})$ or $\mathrm{C}=\mathrm{O}$ species in carboxyl groups of aliphatic organics. The peak located at $533.3 \mathrm{eV}$ can be attributed to the adsorbed water and $\mathrm{C}-\mathrm{O}$ bonding in carboxyl groups of aliphatic organics.

Table 2 shows the functional groups assigned to each binding energy (BE) found in Figure 6, as well as the relative atomic intensities of each one of these species. 
Table 2. XPS binding energies assigned species and their relative surface concentrations obtained from the $\mathrm{C} 1 \mathrm{~s}$ and O1s peak fits in Figure 6 for the Pt/CA (a,b) and Pt/CAK (c, d) catalysts.

\begin{tabular}{|c|c|c|c|c|}
\hline \multirow[b]{2}{*}{ Element } & \multirow[b]{2}{*}{ Assigned Species } & \multirow[b]{2}{*}{$\mathrm{BE}(\mathrm{eV})$} & \multicolumn{2}{|c|}{ Relative Intensity (\%) } \\
\hline & & & $\mathrm{Pt} / \mathrm{CA}$ & Pt/CAK \\
\hline \multirow{7}{*}{$\mathrm{C} 1 \mathrm{~s}$} & $s p^{2}-C$ & 284.6 & 41.7 & 35.3 \\
\hline & $\mathrm{sp}^{3}-\mathrm{C}$ & 284.9 & 17.8 & 10.6 \\
\hline & B shift - C & 285.7 & 4.9 & 4.1 \\
\hline & $\begin{array}{c}\mathrm{C}-\mathrm{C}-\mathrm{OOH} \\
\mathrm{C}-\mathrm{O}-\mathrm{C} / \mathrm{C}-\mathrm{OH}\end{array}$ & 286.5 & 11.0 & 7.0 \\
\hline & $\mathrm{C}=\mathrm{O} / \mathrm{O}-\mathrm{C}-\mathrm{O}$ & 287.9 & 4.7 & 3.2 \\
\hline & $\mathrm{O}=\mathrm{C}-\mathrm{OH} / \mathrm{O}=\mathrm{C}-\mathrm{O}$ & 289.4 & 5.2 & 1.6 \\
\hline & C $\pi-\pi^{*}$ shake-up & 291.3 & 5.3 & 0.3 \\
\hline \multirow{4}{*}{$\mathrm{O} 1 \mathrm{~s}$} & $\begin{array}{c}\mathrm{O}=\mathrm{C}-\mathrm{O}(\text { aromatic }) / \mathrm{Pt}- \\
\mathrm{O}(\mathrm{ads})\end{array}$ & 531.2 & 5.6 & 9.2 \\
\hline & $\begin{array}{c}-\mathrm{OH} / \mathrm{O}-\mathrm{C} / \mathrm{O}=\mathrm{C}- \\
\mathrm{O} \text { (aliphatic) }\end{array}$ & 532.2 & 1.5 & 17.0 \\
\hline & $\mathrm{O}=\mathrm{C}-\mathrm{O} / \mathrm{H}_{2} \mathrm{O}(\mathrm{ads})$ & 533.3 & 1.4 & 9.3 \\
\hline & $\mathrm{CO}_{3}$ & 534.7 & 0.8 & 2.4 \\
\hline
\end{tabular}

The observed $\mathrm{O} / \mathrm{C}$ ratio also showed that the Pt/CAK catalyst $(61.0 \%)$ has a much higher concentration of oxygenated groups than Pt/CA (10.3\%). The Pt/CAK catalyst showed a stronger presence of the oxygen-containing functional groups (Table 2), such as hydroxyls $(17.0 \%)$, quinones $(9.2 \%)$, and ether $(9.3 \%)$. On the other hand, the Pt/CA catalyst showed a high content of graphitic carbon $(17.8 \%)$ and a low contribution of the oxygenated functional groups on its surface, the quinones (5.6\%), hydroxyls (1.5\%), and ether (1.4\%) groups. These results agree with those obtained by FTIR and ToF-SIMS of the samples, which indicated that the materials in CAK have a higher content of oxygenated groups. The lower atomic concentration of functional groups, evidenced in the Pt/CA catalyst, can influence the catalytic activity since the functional groups can contribute to furan species' adsorption and active site regeneration [15].

Following calcination, the $\mathrm{Pt} 4 \mathrm{f}_{7 / 2}$ peak (Figure S-5, Supplementary Materials) showed binding energy of $73.3 \mathrm{eV}$ in the $\mathrm{Pt} / \mathrm{CA}$ and $\mathrm{Pt} / \mathrm{CAK}$ catalysts, indicating the presence of oxidized platinum [48]. However, in the $\mathrm{Pt} / \mathrm{CAK}$ catalyst, the $\mathrm{Pt} 4 \mathrm{f}_{7 / 2}$ peak exhibited binding energy of $71.1 \mathrm{eV}$, consistent with that of metallic platinum [28].



(a)



(b)

Figure 7. TPR profiles: (a) Pt/CA; (b) Pt/CAK.

The XPS spectra have shown the CAK support to exhibit a greater concentration of strong oxidizing groups than the $\mathrm{CA}$, which favors the platinum's higher metallic dispersion and promotes a partial reduction of the metallic precursor. As the acidic aqueous solution of the metal precursor comes into contact with the CA/CAK support, oxidation of the carbon 
surface occurs, and simultaneously the platinum $\left(\mathrm{Pt}^{4+}\right)$ species are partially $\left(\mathrm{Pt}^{2+}-\mathrm{CA}\right)$ or fully $\left(\mathrm{Pt}^{0}-\mathrm{CAK}\right)$ reduced [47].

The reducibility of the metal precursors was assessed by TPR- $\mathrm{H}_{2}$ (Figure 7). Reduction of platinum species to the metallic state occurs between $150-300{ }^{\circ} \mathrm{C}$ [49-52], as seen in Figure 7.

The broad peak in the range of $400-650{ }^{\circ} \mathrm{C}$, shown in Figure 7 , is attributed to the interaction of hydrogen with the surface sites of the supports [49-51], promoting the decomposition of the oxygen-containing functional groups. From these results, a temperature of $300{ }^{\circ} \mathrm{C}$ was determined to form metallic platinum in the catalysts.

The thermal stability of the catalysts was studied by TGA/DTA. Figure 8 shows the profiles of the TGA/DTA curves of the supports and catalysts.

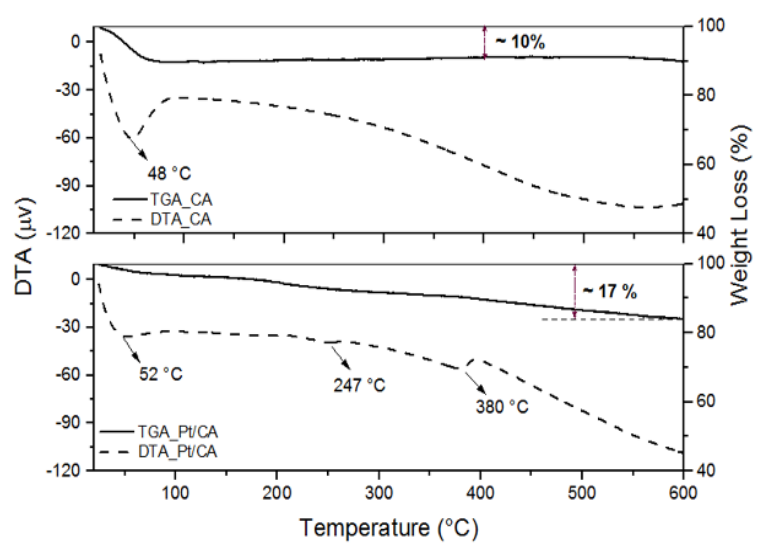

(a)

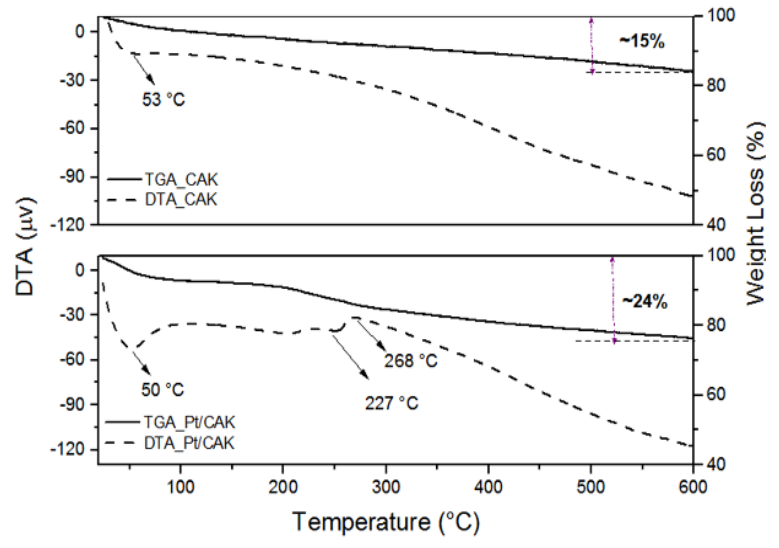

(b)

Figure 8. TGA/DTA curve in $\mathrm{N}_{2}$ for the materials: (a) CA and Pt/CA; (b) CAK and Pt/CAK.

The supports and catalysts showed high thermal stability with a maximum mass loss of $24 \%$ up to $600{ }^{\circ} \mathrm{C}$. The mass loss observed between $25-110{ }^{\circ} \mathrm{C}$ is attributed to the release of water (humidity). Mass loss between $110-600{ }^{\circ} \mathrm{C}$ is associated with the release of $\mathrm{CO}_{2}$ and $\mathrm{CO}$ with the decomposition of oxygen-containing functional groups and other volatile species present in the samples [52]. The CAK support and Pt/CAK catalyst revealed a greater mass loss than the CA support and Pt/CA catalyst due to a higher proportion of oxygen-containing and heteroatom functional groups on the surface of the CAK, which interfere with the thermal stability and hydrophilic character of the material.

Regarding the catalysts, the peaks related to the release of water were also evident $(\mathrm{T}<$ $110{ }^{\circ} \mathrm{C}$ ), while the other peaks were attributed to a degradation of the metal precursor salt $\left(\mathrm{H}_{2} \mathrm{PtCl}_{6}\right)$. Thermal decomposition of $\mathrm{H}_{2} \mathrm{PtCl}_{6}$ in an inert atmosphere occurs over a wide temperature range from $200-550{ }^{\circ} \mathrm{C}$ [53]. Therefore, not considering the peaks related to the decomposition of metallic precursors in the catalysts, it is noted that all catalysts were stable at the reaction temperature $\left(100{ }^{\circ} \mathrm{C}\right)$. This condition favors heat transfer in the reaction medium and a reduced tendency of sintering through heating.

Table 3. HMF Conversion and product yield of CA and CAK support and $\mathrm{Pt} / \mathrm{C}$ and $\mathrm{Pt} / \mathrm{CAK}$ catalysts in aerobic oxidation $^{1 .}$

\begin{tabular}{c|c|c|c|c} 
Entry & Catalyst & $\mathbf{X}_{\mathbf{H M F}} \mathbf{1}^{\mathbf{( \% )}}$ & $\mathbf{Y}_{\text {FDCA }}(\boldsymbol{\%})$ & $\mathbf{Y}_{\text {FFCA }}(\boldsymbol{\%})$ \\
\hline 1 & $\mathrm{CA}^{2}$ & 50.3 & -- & -- \\
\hline 2 & $\mathrm{CAK}^{2}$ & 30.1 & -- & 2.9 \\
\hline 3 & $\mathrm{Pt} / \mathrm{CA}$ & 100 & 31.7 & 44.3 \\
\hline 4 & $\mathrm{Pt} / \mathrm{CAK}$ & 100 & 93.6 & 3.3
\end{tabular}

${ }^{1}$ Reaction conditions: catalyst $(0.3 \mathrm{~g}), \mathrm{NaHCO}_{3}(\sim 0.6 \mathrm{~g}), \mathrm{HMF}\left(10 \mathrm{~g} . \mathrm{L}^{-1}\right), 100{ }^{\circ} \mathrm{C}, 40$ bar synthetic air for $4 \mathrm{~h} .{ }^{2} \mathrm{Blank}$ reactions, without impregnated Pt. 
The results of HMF conversion ( $\mathrm{X}_{\mathrm{HMF}}$ ) and the yields of furan species (Y $\mathrm{FDCA}$ and $Y_{\text {FFCA }}$, obtained using the supports and catalysts, are shown in Table 3.

The supports and catalysts showed different behavior during the reaction. The catalytic conversion on the supports was $50.3 \%$ for CA and $30.1 \%$ for CAK without the formation of FDCA. HMF degradation products (humines and solubilized oligomers) were observed, confirmed by the color change of the reaction mixture from colorless to intense yellow. Other authors have also identified the formation of humines in the oxidation of HMF to FDCA in blank reactions using metal oxide supports and activated carbon [14,54]. These results can be attributed to the low catalytic activity of the supports (without the metal) and the instability of HMF in an alkaline medium.

For the Pt/CA and Pt/CAK catalysts, the conversion was $100 \%$ with the formation of only FDCA and FFCA. The presence of Pt favored a decrease in the degradation of HMF and an increase in the yield of the desired products. The high reactivity of the Pt catalysts, as well as the instability of intermediate species (DFF and HMFCA) in the alkaline medium [5,12], prevented the identification of these species in the reaction mixture.

The formation of FDCA and FFCA from HMF can be represented by two oxidation reaction paths (Figure 9) [16, 54].

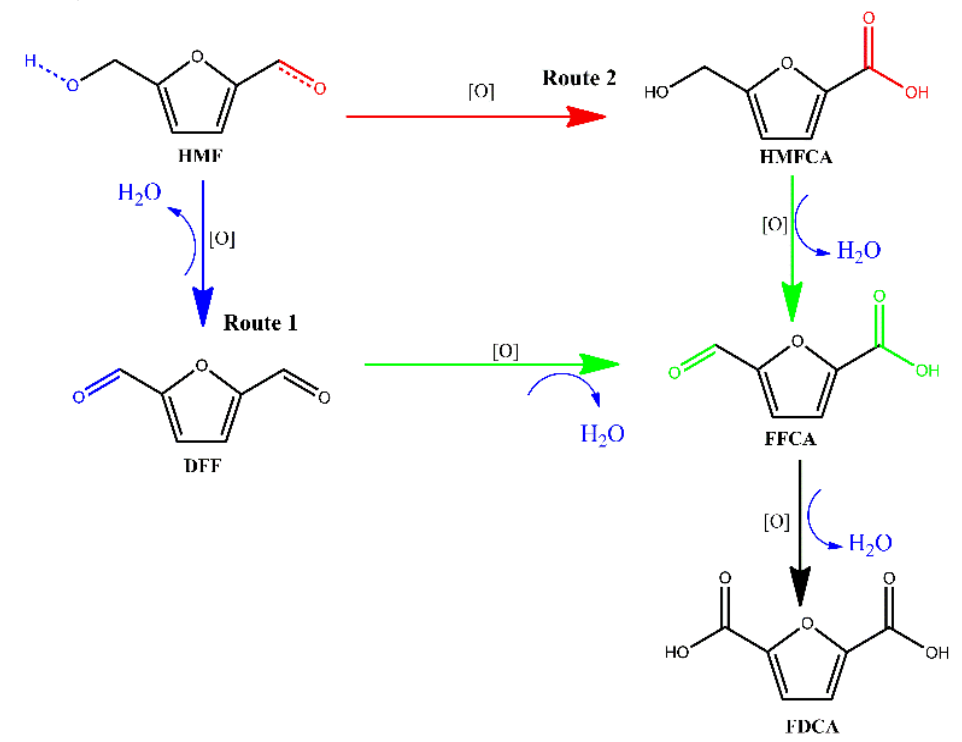

Figure 9. Different reaction paths for HMF oxidation with molecular oxygen.

Depending on the reaction conditions and the catalyst, the conversion of HMF to FDCA can proceed through oxidation of the alcohol group (Route 1) forming the DFF or through the aldehyde group (Route 2) forming HMFCA [18]. These reaction intermediates are then oxidized to FFCA, which in turn is transformed into FDCA. The presence of platinum on the surface of the coal favors a preferential attack on the aldehyde group (Route 2) over the primary alcohol group of HMF [55].

The Pt/CAK catalyst with a greater concentration of oxygen-containing functional groups and higher metallic dispersion was the catalyst that showed the highest yield for FDCA. Figure 10 shows the relationship between the metallic dispersion (TEM analysis) and the oxygen/carbon ratio (XPS analysis) and FDCA yield.

The higher dispersion of platinum and higher O/C ratio obtained in the Pt/CAK catalyst led to a higher FDCA yield (93.6\%) compared to the Pt/CA catalyst (31.7\%).

The supports modify the electronic and geometric properties of the active metals, which influences the activity of the catalysts $[37,56]$. The higher $\mathrm{O} / \mathrm{C}$ ratio of the $\mathrm{Pt} / \mathrm{CAK}$ catalyst 
favored a greater metal-support interaction and enhanced stability of the platinum nanoparticles, which increased the catalytic activity. Higher levels of oxygen-containing functional groups and their proximity to the active metal stabilize the metal, giving a considerably greater Pt-C binding energy [37,57,58].



Figure 10. Relationship between the effects of platinum dispersion and the oxygen/carbon (O/C) ratio on FDCA yield.

When using a Pd/C catalyst, Rao et al. [59] found a positive correlation between the concentration of acid functional groups and metal activity in the hydrogenation of cinnamaldehyde, attributing these results to changes in the charge distribution at the palladiumcarbon interface due to the effect of the functional groups. Regarding metallic dispersion, Prado-Burguete et al. [36], studying the effect of functional groups on Pt/C catalyst on HMF oxidation in FDCA, observed that an increase in metallic dispersion led to a higher formation of FDCA. Similarly, Byun et al. [60], studying the hydrogenation of glucose to sorbitol over $\mathrm{Pt} / \mathrm{C}$ catalyst, also observed a higher selectivity for sorbitol formation $(65.8 \%)$ when using the catalyst with the higher metallic dispersion (58\%).

Thus, the synergistic effect of the increased metallic dispersion and the higher proportion of oxygen-containing groups on the surface $(\mathrm{O} / \mathrm{C}$ ratio) of the Pt/CAK catalyst favored its better catalytic activity. Our results corroborate those found by Sun et al. [58], who attributed the high selectivity in FDCA (> 99\%) over the Pt/HT-C catalyst to the high metallic dispersion and the presence of oxygen-containing functional groups (hydroxyl, quinone, and lactone) in the support.

From the results obtained, a mechanistic reaction route can be proposed. Reaction studies were carried out with a shorter reaction time $(2 \mathrm{~h})$ to identify the possible reaction routes of HMF oxidation (Figure 9) under the same temperature and pressure conditions. In these conditions, the formation of the HMFCA Figure S-6 (Supplementary Materials) was observed due to preferential oxidation of the HMF aldehyde group (Route 2, Figure 9). Zhou et al. [15], studying the oxidation of HMF to FDCA on platinum supported by CNTs, observed that the oxidation of the aldehyde functional group is faster than that of the hydroxyl group in an alkaline medium. Thus, a proposal for a mechanical route of oxidation from HMF to FDCA is shown in Figure 11.

The first stage of the mechanism (Figure 11, path 1) involves oxidative dehydrogenation of gem-diol adsorbed to the metal and the formation of carboxylic acid (HMFCA) [7,13]. 
Path 1: Formation of HMFCA from gemdiol-HMF.

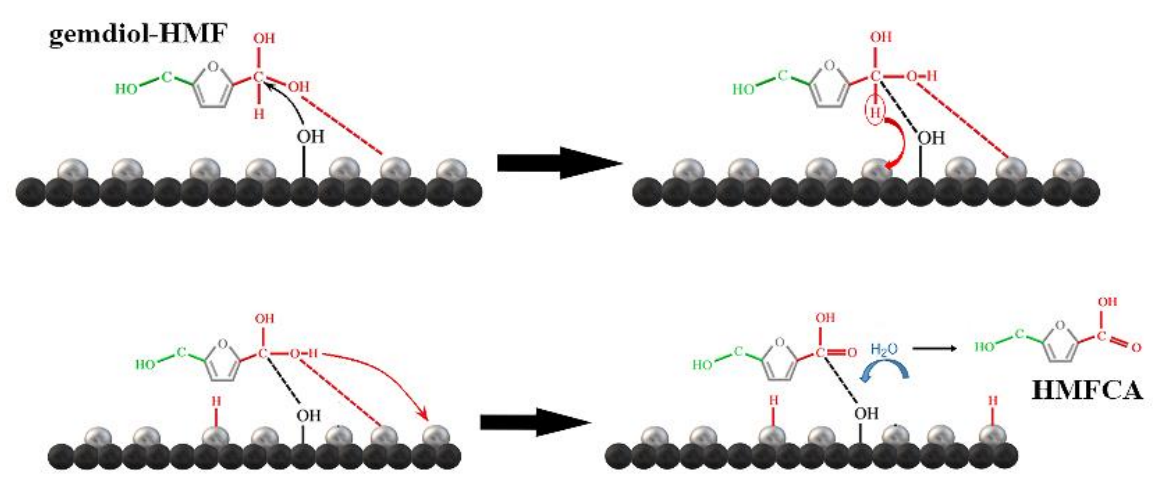

Path 2: Formation of FFCA from HMFCA.

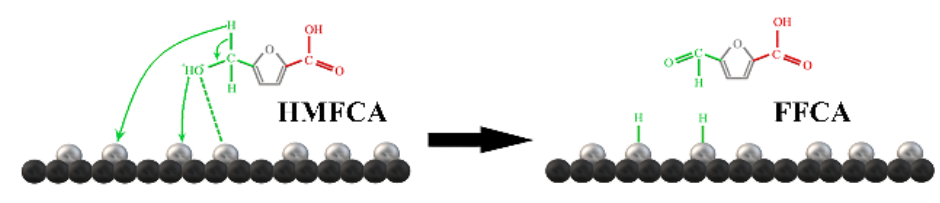

Path 3: Formation of FDCA from FFCA.


Figure 11. Possible reaction mechanism for HMF oxidation in alkaline medium.

The formation of gem-diol is the result of hydration of the HMF aldehyde group in an alkaline medium [3,13]. Hydroxyl groups of the support may also favor the formation of gemdiol [58]. However, it appears that these groups act mainly on the adsorption of gem-diol to the platinum surface $\left(\mathrm{Pt}^{0}\right)$ due to its nucleophilic character, thus facilitating the oxidative dehydrogenation reaction. Davis et al. [61], when studying the oxidation of HMF to FDCA with the $\mathrm{Pt} / \mathrm{C}$ catalyst, also suggested the influence of the $\mathrm{OH}$ group of the support on the adsorption of gem-diol. Vinke et al. [62] reported the importance of hydrating the aldehyde group for HMF oxidation because when not hydrated, the aldehyde group becomes stable due to the resonance effect of the HMF aromatic ring. Finally, the HMFCA formed on the metallic surface is desorbed by the hydrolysis of water [63].

The two hydrogen atoms removed from the gem-diol molecule during oxidative dehydrogenation are adsorbed on the surface of neighboring active sites, blocking them by forming metal hydrides. Compared to phenolic groups, the greater reduction potential of quinone groups confirms their better activity as active redox mediators in removing these atoms and, consequently, in the release of the catalytic site $[64,65]$. Quinone is easily reduced to hydroquinone and is capable of being regenerated by molecular oxygen.

A similar result was found by Zhou et al. [15], who also attributed the high performance of the Pt/CNT catalyst in the FDCA formation (98\% selectivity) to the functional groups 
(carbonyls/quinones and phenolics) incorporated in the support, which facilitated the adsorption of HMF and the abstraction of hydrogen protons from the active sites.

The second stage (Figure 11, path 2) consisted of oxidizing the alcohol group of the HMFCA to aldehyde, generating FFCA $[3,15,61]$. The hydroxyl group of the HMFCA is adsorbed on the surface of the metallic platinum, and then the activated $\mathrm{C}-\mathrm{H}$ bond and the FFCA are formed through the B-hydride elimination reaction. This is the slowest step of the reaction. Ardemani et al. [66], when studying different conditions in the oxidation of HMF to FDCA under an Au/HT catalyst in an aqueous medium, concluded that this kinetic limitation is due to the high activation energy reaction step $\left(40 \mathrm{~kJ}^{\mathrm{mol}}{ }^{-1}\right)$.

The third stage (Figure 11, path 3) involves oxidation of the aldehyde group of the FFCA to the carboxylic acid, FDCA. Therefore, the reaction mechanism is similar to the first stage (Figure 11, path 1). The role of molecular oxygen in the reaction is the removal of hydrogen ion $\left(\mathrm{H}^{+}\right)$adsorbed on the platinum surface after dehydrogenation reactions $[4,16,61]$, regenerating the active phase $\left(\mathrm{Pt}^{0}\right)$ and reduced functional groups (the hydroquinones). Water is responsible for the incorporation of oxygen into the furan products formed. Previous studies based on isotopic labeling have shown that molecular oxygen is not incorporated into the furanbased molecules formed but is derived from water $[3,61,67]$.

The activation of metallic platinum in the oxidation of HMF and its furan intermediates with a high FDCA yield results from the synergism between (i) the contribution of hydroxyl groups to the adsorption of furan species; and (ii) the quinone groups, for the abstraction of hydrogen ions in the Pt/CAK catalyst; leading to a reduction in the energy barrier for adsorption of furan species at the active site.

\section{Conclusions}

The Pt/CAK catalyst was more active than Pt/CA in the oxidation reaction of 5-HMF into FDCA. The results were attributed to the synergistic effect of the support's high metallic dispersion and high oxygen/carbon ratio (due to a greater concentration of oxygen-containing functional groups), which facilitated the Pt-HMF interaction, furan Pt-intermediates and hydrogen ion abstraction on the active surface.

\section{Funding}

This research received no external funding.

\section{Acknowledgments}

The authors would like to thank CAPES - Finance Code 001 (Coordenação de Aperfeiçoamento de Pessoal de Nivel Superior - Brasil) and IBTR (Instituto Brasileiro de Tecnologia e Regulação) for financial support. Special thanks to CBMM for supplying the niobium catalysts. The authors would also like to thank the LAMUME/UFBA for SEM analysis, LCE/UFSCAR for TEM analysis, Steven Hinder from the University of Surrey for XPS and TOF-SIMS analysis, and LOA/UFPA for assigning the CAK for the study.

\section{Conflicts of Interest}

The authors declare no conflict of interest. 


\section{References}

1. 2,5-Furandicarboxylic Acid (FDCA) Market Size, Trends \& Analysis, By Application (PET, Polyamides, Polycarbonates, Plasticizers, Polyesters Polyols, And Others), By End-User (Chemical, Pharmaceutical, Scientific Research), By Method (Dehydration Of Hexose Derivatives, Oxidation Of 2,5-Distributed Furans, Catalytic Conversions Of Various Furan Derivatives, Biological Conversion Of HMF, By Channel (Direct Sales, Distribution), By Region Forecast To 2027. Available online: https://www.reportsanddata.com/reportdetail/2-5-furandicarboxylic-acid-fdca-market (accessed 20 December 2020).

2. Chen, C.; Wang, L.; Zhu, B.; Zhou, Z.; El-Hout, S.I.; Yang, J.; Zhang, J. 2,5-Furandicarboxylic acid production via catalytic oxidation of 5-hydroxymethylfurfural: Catalysts, processes and reaction mechanism. Journal of Energy Chemistry 2021, 54, 528-554, https://doi.org/10.1016/j.jechem.2020.05.068.

3. Sajid, M.; Zhao, X.; Liu, D. Production of 2,5-furandicarboxylic acid (FDCA) from 5-hydroxymethylfurfural (HMF): recent progress focusing on the chemical-catalytic routes. Green Chem. 2018, 20, 5427-5453, https://doi.org/10.1039/c8gc02680g.

4. Zhou, H.; Xu, H.; Liu, Y. Aerobic oxidation of 5-hydroxymethylfurfural to 2,5-furandicarboxylic acid over Co/Mn-lignin coordination complexes-derived catalysts. Applied Catalysis B: Environmental 2019, 244, $965-$ 973, https://doi.org/10.1016/j.apcatb.2018.12.046.

5. Zhao, D.; Su, T.; Wang, Y.; Varma, R.S.; Len, C. Recent advances in catalytic oxidation of 5$\begin{array}{lllll}\text { hydroxymethylfurfural. } & \text { Molecular } & \text { Catalysis } & \mathbf{2 0 2 0}, & 495,\end{array}$ https://doi.org/10.1016/j.mcat.2020.111133.

6. Sharma, P.; Solanki, M.; Sharma, R.K. Metal-functionalized carbon nanotubes for biomass conversion: basefree highly efficient and recyclable catalysts for aerobic oxidation of 5-hydroxymethylfurfural. New J. Chem. 2019, 43, 10601-10609, https://doi.org/10.1039/c9nj01555h.

7. Danielli da Fonseca Ferreira, A.; Dorneles de Mello, M.; da Silva, M.A.P. Catalytic Oxidation of 5Hydroxymethylfurfural to 2,5-Furandicarboxylic acid over $\mathrm{Ru} / \mathrm{Al}_{2} \mathrm{O}_{3}$ in a Trickle-Bed Reactor. Ind. Eng. Chem. Res. 2019, 58, 128-137, https://doi.org/10.1021/acs.iecr.8b05602.

8. Zhu, Z.; Gao, X.; Wang, X.; Yin, M.; Wang, Q.; Ren, W.; Wang, B.; Lü, H.; Liao, W. Rational construction of metal-base synergetic sites on Au/Mg-beta catalyst for selective aerobic oxidation of 5hydroxymethylfurfural. Journal of Energy Chemistry 2021, 62, 599-609, https://doi.org/10.1016/j.jechem.2021.04.022.

9. Han, X.; Geng, L.; Guo, Y.; Jia, R.; Liu, X.; Zhang, Y.; Wang, Y. Base-free aerobic oxidation of 5hydroxymethylfurfural to 2,5-furandicarboxylic acid over a Pt/C-O-Mg catalyst. Green Chem. 2016, 18, 1597-1604, https://doi.org/10.1039/c5gc02114f.

10. Liu, X.; Chen, L.; Xu, H.; Jiang, S.; Zhou, Y.; Wang, J. Straightforward synthesis of beta zeolite encapsulated Pt nanoparticles for the transformation of 5-hydroxymethyl furfural into 2,5-furandicarboxylic acid. Chinese Journal of Catalysis 2021, 42, 994-1003, https://doi.org/10.1016/S1872-2067(20)63720-2.

11. Vinke, P.; van der Poel, W.; van Bekkum, H. On the oxygen tolerance of noble metal catalysts in liquid phase alcohol oxidations the influence of the support on catalyst deactivation. In Stud. Surf. Sci. Catal., Guisnet, M., Barrault, J., Bouchoule, C., Duprez, D., Pérot, G., Maurel, R., Montassier, C., Eds. Elsevier: 1991; 59, 385-394, https://doi.org/10.1016/S0167-2991(08)61145-3.

12. da Silva, E.D.; Gonzalez, W.A.; Fraga, M.A. Aqueous-phase oxidation of 5-hydroxymethylfurfural over $\mathrm{Pt} / \mathrm{ZrO}_{2}$ catalysts: exploiting the alkalinity of the reaction medium and catalyst basicity. Green Processing and Synthesis 2016, 5, 353-364, https://doi.org/10.1515/gps-2016-0010.

13. Liao, Y.-T.; Nguyen, V.C.; Ishiguro, N.; Young, A.P.; Tsung, C.-K.; Wu, K.C.W. Engineering a homogeneous alloy-oxide interface derived from metal-organic frameworks for selective oxidation of 5hydroxymethylfurfural to 2,5-furandicarboxylic acid. Applied Catalysis B: Environmental 2020, 270, 118805, https://doi.org/10.1016/j.apcatb.2020.118805.

14. Kerdi, F.; Ait Rass, H.; Pinel, C.; Besson, M.; Peru, G.; Leger, B.; Rio, S.; Monflier, E.; Ponchel, A. Evaluation of surface properties and pore structure of carbon on the activity of supported Ru catalysts in the aqueous-phase aerobic oxidation of HMF to FDCA. Applied Catalysis A: General 2015, 506, 206-219, https://doi.org/10.1016/j.apcata.2015.09.002.

15. Zhou, C.; Deng, W.; Wan, X.; Zhang, Q.; Yang, Y.; Wang, Y. Functionalized Carbon Nanotubes for Biomass Conversion: The Base-Free Aerobic Oxidation of 5-Hydroxymethylfurfural to 2,5-Furandicarboxylic Acid over Platinum Supported on a Carbon Nanotube Catalyst. ChemCatChem 2015, 7, 2853-2863, https://doi.org/10.1002/cctc.201500352. 
16. Donoeva, B.; Masoud, N.; de Jongh, P.E. Carbon Support Surface Effects in the Gold-Catalyzed Oxidation of 5-Hydroxymethylfurfural. ACS Catalysis 2017, 7, 4581-4591, https://doi.org/10.1021/acscatal.7b00829.

17. Teng, N.; Li, J.-1.; Lu, B.-q.; Wang, Y.-q.; Jia, S.-y.; Wang, Y.-X.; Hou, X.-1. The selective aerobic oxidation of 5-hydroxymethylfurfural to produce 2,5-diformylfuran using Nitrogen-doped porous carbons as catalysts. New Carbon Materials 2019, 34, 593-599, https://doi.org/10.1016/S1872-5805(19)60034-X.

18. Yang, C.; Li, X.; Zhang, Z.; Lv, B.; Li, J.; Liu, Z.; Zhu, W.; Tao, F.; Lv, G.; Yang, Y. Utilization of biomass waste: Facile synthesis high nitrogen-doped porous carbon from pomelo peel and used as catalyst support for aerobic oxidation of 5-hydroxymethylfurfural. Fuel 2020, 278, 118361, https://doi.org/10.1016/j.fuel.2020.118361.

19. Sato, M.K.; de Lima, H.V.; Costa, A.N.; Rodrigues, S.; Pedroso, A.J.S.; de Freitas Maia, C.M.B. Biochar from Acai agroindustry waste: Study of pyrolysis conditions. Waste Manage. 2019, 96, 158-167, https://doi.org/10.1016/j.wasman.2019.07.022.

20. Sato, M.K.; de Lima, H.V.; Noronha Costa, A.; Rodrigues, S.; Mooney, S.J.; Clarke, M.; Silva Pedroso, A.J.; de Freitas Maia, C.M.B. Biochar as a sustainable alternative to açaí waste disposal in Amazon, Brazil. Process Saf. Environ. Prot. 2020, 139, 36-46, https://doi.org/10.1016/j.psep.2020.04.001.

21. Reis, J.S.; Araujo, R.O.; Lima, V.M.R.; Queiroz, L.S.; da Costa, C.E.F.; Pardauil, J.J.R.; Chaar, J.S.; Rocha Filho, G.N.; de Souza, L.K.C. Combustion properties of potential Amazon biomass waste for use as fuel. $J$. Therm. Anal. Calorim. 2019, 138, 3535-3539, https://doi.org/10.1007/s10973-019-08457-5.

22. de Sousa Ribeiro, L.A.; Thim, G.P.; Alvarez-Mendez, M.O.; dos Reis Coutinho, A.; de Moraes, N.P.; Rodrigues, L.A. Preparation, characterization, and application of low-cost açaí seed-based activated carbon for phenol adsorption. International Journal of Environmental Research 2018, 12, 755-764, https://doi.org/10.1007/s41742-018-0128-5.

23. Queiroz, L.S.; de Souza, L.K.C.; Thomaz, K.T.C.; Leite Lima, E.T.; da Rocha Filho, G.N.; do Nascimento, L.A.S.; de Oliveira Pires, L.H.; Faial, K.d.C.F.; da Costa, C.E.F. Activated carbon obtained from amazonian biomass tailings (acai seed): Modification, characterization, and use for removal of metal ions from water. $J$. Environ. Manage. 2020, 270, 110868, https://doi.org/10.1016/j.jenvman.2020.110868.

24. Ello, A.S.; de Souza, L.K.C.; Trokourey, A.; Jaroniec, M. Development of microporous carbons for CO2 capture by $\mathrm{KOH}$ activation of African palm shells. Journal of $\mathrm{CO}_{2}$ Utilization 2013, 2, 35-38, https://doi.org/10.1016/j.jcou.2013.07.003.

25. Wang, D.; Zhu, Y. An Effective Pt-Cu/SiO<sub $>2</ \mathrm{sub}>$ Catalyst for the Selective Hydrogenation of Cinnamaldehyde. Journal of Chemistry 2018, 2018, 5608243, https://doi.org/10.1155/2018/5608243.

26. Thommes, M.; Kaneko, K.; Neimark, A.V.; Olivier, J.P.; Rodriguez-Reinoso, F.; Rouquerol, J.; Sing, K.S.W. Physisorption of gases, with special reference to the evaluation of surface area and pore size distribution (IUPAC Technical Report). Pure Appl. Chem. 2015, 87, 1051-1069, https://doi.org/10.1515/pac-2014-1117.

27. Liu, Z.; Sun, Y.; Xu, X.; Meng, X.; Qu, J.; Wang, Z.; Liu, C.; Qu, B. Preparation, characterization and application of activated carbon from corn cob by $\mathrm{KOH}$ activation for removal of $\mathrm{Hg}$ (II) from aqueous solution. Bioresour. Technol. 2020, 306, 123154, https://doi.org/10.1016/j.biortech.2020.123154.

28. Silva, L.A.d.; Borges, S.M.S.; Paulino, P.N.; Fraga, M.A.; Oliva, S.T.d.; Marchetti, S.G.; Rangel, M.d.C. Methylene blue oxidation over iron oxide supported on activated carbon derived from peanut hulls. Catal. Today 2017, 289, 237-248, https://doi.org/10.1016/j.cattod.2016.11.036.

29. Zhao, H.; Cheng, Y.; Zhang, Z.; Zhang, B.; Pei, C.; Fan, F.; Ji, G. Biomass-derived graphene-like porous carbon nanosheets towards ultralight microwave absorption and excellent thermal infrared properties. Carbon 2021, 173, 501-511, https://doi.org/10.1016/j.carbon.2020.11.035.

30. Arcanjo, M.R.A.; Silva, I.J.; Rodríguez-Castellón, E.; Infantes-Molina, A.; Vieira, R.S. Conversion of glycerol into lactic acid using Pd or Pt supported on carbon as catalyst. Catal. Today 2017, 279, 317-326, https://doi.org/10.1016/j.cattod.2016.02.015.

31. Mopoung, S.; Moonsri, P.; Palas, W.; Khumpai, S. Characterization and Properties of Activated Carbon Prepared from Tamarind Seeds by $\mathrm{KOH}$ Activation for Fe(III) Adsorption from Aqueous Solution. The Scientific World Journal 2015, 2015, 415961, https://doi.org/10.1155/2015/415961.

32. Villa, A.; Schiavoni, M.; Campisi, S.; Veith, G.M.; Prati, L. Pd-modified Au on Carbon as an Effective and Durable Catalyst for the Direct Oxidation of HMF to 2,5-Furandicarboxylic Acid. ChemSusChem 2013, 6 , 609-612, https://doi.org/10.1002/cssc.201200778.

33. Dehkhoda, A.M.; Ellis, N.; Gyenge, E. Effect of activated biochar porous structure on the capacitive deionization of $\mathrm{NaCl}$ and $\mathrm{ZnCl}_{2}$ solutions. Microporous Mesoporous Mater. 2016, 224, 217-228, https://doi.org/10.1016/j.micromeso.2015.11.041. 
34. Feng, Y.; Liu, L.; Yang, Y.; Deng, Y.; Li, K.; Cheng, H.; Dong, X.; Li, W.; Zhang, L. The application of Raman spectroscopy combined with multivariable analysis on source apportionment of atmospheric black carbon aerosols. Sci. Total Environ. 2019, 685, 189-196, https://doi.org/10.1016/j.scitotenv.2019.05.367.

35. Gonçalves, E.S.; Rezende, M.C.; Baldan, M.R.; Ferreira, N.G. Efeito do tratamento térmico na microestrutura, turbostraticidade e superfície de carbono vítreo reticulado analisado por XPS, espalhamento Raman e voltametria cíclica. Quim. Nova 2009, 32, 158-164, https://doi.org/10.1590/S010040422009000100030.

36. Prado-Burguete, C.; Linares-Solano, A.; Rodríguez-Reinoso, F.; de Lecea, C.S.-M. The effect of oxygen surface groups of the support on platinum dispersion in Pt/carbon catalysts. J. Catal. 1989, 115, 98-106, https://doi.org/10.1016/0021-9517(89)90010-9.

37. Gerber, I.C.; Serp, P. A Theory/Experience Description of Support Effects in Carbon-Supported Catalysts. Chem. Rev. 2020, 120, 1250-1349, https://doi.org/10.1021/acs.chemrev.9b00209.

38. Oliveira, G.F.d.; Andrade, R.C.d.; Trindade, M.A.G.; Andrade, H.M.C.; Carvalho, C.T.d. Thermogravimetric and spectroscopic study (TG-DTA/FT-IR) of activated carbon from the renewable biomass source babassu. Quim. Nova 2017, 40, 284-292, https://doi.org/10.21577/0100-4042.20160191.

39. Velasco, L.F.; Devos, A.; Lodewyckx, P. The importance of outgassing conditions when using water vapour to characterize activated carbons. Carbon 2019, 152, 409-415, https://doi.org/10.1016/j.carbon.2019.06.054.

40. Puziy, A.M.; Poddubnaya, O.I.; Martínez-Alonso, A.; Suárez-García, F.; Tascón, J.M.D. Surface chemistry of phosphorus-containing carbons of lignocellulosic origin. Carbon 2005, 43, 2857-2868, https://doi.org/10.1016/j.carbon.2005.06.014.

41. Okolo, G.N.; Neomagus, H.W.J.P.; Everson, R.C.; Roberts, M.J.; Bunt, J.R.; Sakurovs, R.; Mathews, J.P. Chemical-structural properties of South African bituminous coals: Insights from wide angle XRD-carbon fraction analysis, ATR-FTIR, solid state 13C NMR, and HRTEM techniques. Fuel 2015, 158, 779-792, https://doi.org/10.1016/j.fuel.2015.06.027.

42. Guilarduci, V.V.d.S.; Mesquita, J.P.d.; Martelli, P.B.; Gorgulho, H.d.F. Phenol adsorption on commercial active carbon under alkaline conditions. Quim. Nova 2006, 29, 1226-1232, https://doi.org/10.1590/S010040422006000600015.

43. Lima, S.B.; Borges, S.M.S.; Rangel, M.d.C.; Marchetti, S.G. Effect of iron content on the catalytic properties of activated carbon-supported magnetite derived from biomass. J. Braz. Chem. Soc. 2013, 24, 344-354, https://doi.org/10.5935/0103-5053.20130044.

44. Mistar, E.M.; Alfatah, T.; Supardan, M.D. Synthesis and characterization of activated carbon from Bambusa vulgaris striata using two-step KOH activation. Journal of Materials Research and Technology 2020, 9, 62786286, https://doi.org/10.1016/j.jmrt.2020.03.041.

45. Barroso-Bogeat, A.; Alexandre-Franco, M.; Fernández-González, C.; Gómez-Serrano, V. Activated carbon surface chemistry: Changes upon impregnation with $\mathrm{Al}(\mathrm{III}), \mathrm{Fe}(\mathrm{III})$ and $\mathrm{Zn}$ (II)-metal oxide catalyst precursors from $\mathrm{NO}_{3}^{-}$aqueous solutions. Arabian Journal of Chemistry 2019, 12, 3963-3976, https://doi.org/10.1016/j.arabjc.2016.02.018.

46. Domingues, R.R.; Trugilho, P.F.; Silva, C.A.; Melo, I.C.N.A.d.; Melo, L.C.A.; Magriotis, Z.M.; SánchezMonedero, M.A. Properties of biochar derived from wood and high-nutrient biomasses with the aim of agronomic and environmental benefits. PLoS One 2017, 12, e0176884, https://doi.org/10.1371/journal.pone.0176884.

47. High Resolution XPS of Organic Polymers: The Scienta ESCA300 Database (Beamson, G.; Briggs, D.). J. Chem. Educ. 1993, 70, A25, https://doi.org/10.1021/ed070pA25.5.

48. Han, X.; Li, C.; Guo, Y.; Liu, X.; Zhang, Y.; Wang, Y. N-doped carbon supported Pt catalyst for base-free oxidation of 5-hydroxymethylfurfural to 2,5-furandicarboxylic acid. Applied Catalysis A: General 2016, 526, 1-8, https://doi.org/10.1016/j.apcata.2016.07.011.

49. Sepúlveda-Escribano, A.; Coloma, F.; Rodríguez-Reinoso, F. Platinum catalysts supported on carbon blacks with different surface chemical properties. Appl. Catalysis A: General 1998, 173, 247-257, https://doi.org/10.1016/S0926-860X(98)00183-5.

50. Vilella, I.M.J.; de Miguel, S.R.; Scelza, O.A. Study of the performance of Pt catalysts supported on activated carbon felt and granular carbon for nitrobenzene hydrogenation. Chem. Eng. J. 2005, 114, 33-38, https://doi.org/10.1016/j.cej.2005.08.011.

51. Álvarez-Montero, M.A.; Gómez-Sainero, L.M.; Juan-Juan, J.; Linares-Solano, A.; Rodriguez, J.J. Gas-phase hydrodechlorination of dichloromethane with activated carbon-supported metallic catalysts. Chem. Eng. J. 2010, 162, 599-608, https://doi.org/10.1016/j.cej.2010.06.002. 
52. Kumar, M.; Tamilarasan, R. Modeling of experimental data for the adsorption of methyl orange from aqueous solution using a low cost activated carbon prepared from Prosopis juliflora. Polish Journal of Chemical Technology 2013, 15, 29-39, https://doi.org/10.2478/pjct-2013-0021.

53. Kinoshita, K.; Routsis, K.; Bett, J.A.S. The thermal decomposition of platinum(II) and (IV) complexes. Thermochim. Acta 1974, 10, 109-117, https://doi.org/10.1016/0040-6031(74)85029-X.

54. Albonetti, S.; Lolli, A.; Morandi, V.; Migliori, A.; Lucarelli, C.; Cavani, F. Conversion of 5hydroxymethylfurfural to 2,5-furandicarboxylic acid over Au-based catalysts: Optimization of active phase and metal-support interaction. Applied Catalysis B: Environmental 2015, 163, 520-530, https://doi.org/10.1016/j.apcatb.2014.08.026.

55. Mallat, T.; Baiker, A. Oxidation of alcohols with molecular oxygen on platinum metal catalysts in aqueous solutions. Catal. Today 1994, 19, 247-283, https://doi.org/10.1016/0920-5861(94)80187-8.

56. Zhao, X.; Gunji, T.; Kaneko, T.; Takao, S.; Sakata, T.; Higashi, K.; Yoshida, Y.; Ge, J.; Liu, C.; Xing, W.; Zhu, J.; Xiao, M.; Uruga, T.; Tao, F.; Chen, Z. Evidence for interfacial geometric interactions at metalsupport interfaces and their influence on the electroactivity and stability of Pt nanoparticles. Journal of Materials Chemistry A 2020, 8, 1368-1377, https://doi.org/10.1039/c9ta12456j.

57. Mahmoodinia, M.; Åstrand, P.-O.; Chen, D. Tuning the Electronic Properties of Single-Atom Pt Catalysts by Functionalization of the Carbon Support Material. The Journal of Physical Chemistry C 2017, 121, 2080220812, https://doi.org/10.1021/acs.jpcc.7b05894.

58. Sun, W.; Gao, T.; Zhu, G.; Cao, Q.; Fang, W. Influence of Support Properties and Particle Size on the GoldCatalyzed Base-Free Aerobic Oxidation of 5-Hydroxymethylfurfural. ChemistrySelect 2020, 5, 1416-1423, https://doi.org/10.1002/slct.201904497.

59. Rao, R.G.; Blume, R.; Hansen, T.W.; Fuentes, E.; Dreyer, K.; Moldovan, S.; Ersen, O.; Hibbitts, D.D.; Chabal, Y.J.; Schlögl, R.; Tessonnier, J.-P. Interfacial charge distributions in carbon-supported palladium catalysts. Nature Communications 2017, 8, 340, https://doi.org/10.1038/s41467-017-00421-X.

60. Byun, M.Y.; Park, D.-W.; Lee, M.S. Effect of sodium propionate as a stabilizer on the catalytic activity of $\mathrm{Pt} / \mathrm{C}$ catalysts for d-glucose hydrogenation. Catal. Today 2020, 352, 88-94, https://doi.org/10.1016/j.cattod.2019.12.039.

61. Davis, S.E.; Benavidez, A.D.; Gosselink, R.W.; Bitter, J.H.; de Jong, K.P.; Datye, A.K.; Davis, R.J. Kinetics and mechanism of 5-hydroxymethylfurfural oxidation and their implications for catalyst development. J. Mol. Catal. A: Chem. 2014, 388-389, 123-132, https://doi.org/10.1016/j.molcata.2013.09.013.

62. Vinke, P.; Wit, D.d.; de Goede, A.T.J.W.; Bekkum, H.v. Noble Metal Catalyzed Oxidation of Carbohydrates and Carbohydrate Derivatives. In Stud. Surf. Sci. Catal., Ruiz, P., Delmon, B., Eds. Elsevier: 1992; 72, 1-20, https://doi.org/10.1016/S0167-2991(08)61654-7.

63. Wang, Y.; Yu, K.; Lei, D.; Si, W.; Feng, Y.; Lou, L.-L.; Liu, S. Basicity-Tuned Hydrotalcite-Supported Pd Catalysts for Aerobic Oxidation of 5-Hydroxymethyl-2-furfural under Mild Conditions. ACS Sustainable Chemistry \& Engineering 2016, 4, 4752-4761, https://doi.org/10.1021/acssuschemeng.6b00965.

64. Tessensohn, M.E.; Hirao, H.; Webster, R.D. Electrochemical Properties of Phenols and Quinones in Organic Solvents are Strongly Influenced by Hydrogen-Bonding with Water. The Journal of Physical Chemistry C 2013, 117, 1081-1090, https://doi.org/10.1021/jp311007m.

65. Zhang, Y.; Zhang, Z.; Liu, W.; Chen, Y. New applications of quinone redox mediators: Modifying naturederived materials for anaerobic biotransformation process. Sci. Total Environ. 2020, 744, 140652, https://doi.org/10.1016/j.scitotenv.2020.140652.

66. Ardemani, L.; Cibin, G.; Dent, A.J.; Isaacs, M.A.; Kyriakou, G.; Lee, A.F.; Parlett, C.M.A.; Parry, S.A.; Wilson, K. Solid base catalysed 5-HMF oxidation to 2,5-FDCA over Au/hydrotalcites: fact or fiction? Chemical Science 2015, 6, 4940-4945, https://doi.org/10.1039/c5sc00854a.

67. Giannakoudakis, D.A.; Nair, V.; Khan, A.; Deliyanni, E.A.; Colmenares, J.C.; Triantafyllidis, K.S. Additivefree photo-assisted selective partial oxidation at ambient conditions of 5-hydroxymethylfurfural by manganese (IV) oxide nanorods. Applied Catalysis B: Environmental 2019, 256, 117803, https://doi.org/10.1016/j.apcatb.2019.117803. 